\title{
In situ studies on physiology and behaviour in two colour forms of the shore crab Carcinus maenas in relation to season
}

\author{
B. Styrishave*, A. Aagaard, O. Andersen \\ Department of Life Sciences and Chemistry, Roskilde University, PO Box 260, 4000 Roskilde, Denmark
}

\begin{abstract}
Heart rate and locomotor activity were monitored continuously in situ in male green and red colour forms of the shore crab Carcinus maenas along with simultaneous recordings of light intensity, temperature, depth and salinity in the shallow, weakly tidal Isefjord, Denmark. Experiments were conducted during 2 seasons, summer and late autumn. Circatidal and/or circadian rhythmicity in heart rate and/or locomotor activity was observed in $87 \%$ of all crabs during summer and in $55 \%$ of all crabs during autumn. During summer, $45 \%$ of the green crabs and $17 \%$ of the red crabs had significantly higher heart rates during high tide than during low tide. During autumn, $30 \%$ of the green crabs had significantly higher heart rates during high tide than during low tide $(\mathrm{p}<0.05)$. This was never observed in red crabs. Furthermore, $45 \%$ of green and $42 \%$ of red crabs expressed a diurnal variation in heart rate during summer. During autumn, this was observed in $40 \%$ of the green and $30 \%$ of the red crabs. For both colour forms, heart rate levels were significantly higher during summer than during autumn $(p<0.001)$. For the temperature interval 4 to $25^{\circ} \mathrm{C}, Q_{10}$ for heart rate was 2.14 . No significant difference was observed between colour forms. A tight coupling was found between heart rate and locomotor activity, heart rate increased at times with increased locomotor activity. Temperature was the abiotic variable found to exert the largest influence on heart rate and locomotor activity, followed by depth, light and salinity.
\end{abstract}

KEY WORDS: Carcinus maenas $\cdot$ Colour forms $\cdot$ Heart rate $\cdot$ Locomotor activity $\cdot$ Rhythmic variation

\section{INTRODUCTION}

The shore crab Carcinus maenas is common in fjords and estuaries, where it can be found subtidally as well as intertidally (Crothers 1968). This zonation varies with respect to moult stage, sex and size/age, but is also related to tidal, diel and seasonal changes in the marine environment.

Two distinct morphs can be recognised in the shore crab, a 'green' morph and a 'red' morph related to the duration of the intermoult. During moult the crabs form a new exoskeleton with a green colour. The colour gradually changes into a darker redish colour during intermoult. In some crabs, however, intermoult may be prolonged, resulting in a dark red or brown colouration. Red crabs are generally heavier than green crabs (Crothers 1968). Also, they have a thicker carapace and heavier chelae with higher dry weight (Kaiser et al. 1990). When competing for access to females during

•E-mail: styris@virgil.ruc.dk the mating season red crabs will often outcompete green males (Reid et al. 1997).

Green male shore crabs often occur in large numbers in the intertidal zone and express a tidal migration pattern, entering the intertidal zone at high tide and leaving again before low tide (Dare \& Edwards 1981, Hunter \& Naylor 1993, Warman et al. 1993). Red males on the other hand are predominantly found subtidally and only to a lesser extent express a tidal migration pattern. Some green females also migrate into the tidal zone during high tide, but, in general, most females are found subtidally irrespective of colouration. Juveniles are often located in the intertidal zone, close to the shore (Crothers 1968). Shore crabs also appear to have a diurnal rhythm in their migration pattern, being more active during night than during day (Aschoff 1963). More crabs therefore migrate into the intertidal zone during night-time high tides than during daytime high tides. These rhythmic migration patterns are easily observed in environments where changes in the water levels from high tide to low tide are several 
meters. This behaviour can, however, also be observed in weakly tidal zones, where differences in water levels may be less than $0.5 \mathrm{~m}$ (Aagaard et al. 1995a). This rhythmic activity pattern therefore seems to be an integral part of shore crab behaviour, and studies have demonstrated that shore crabs express endogenous circatidal and circadian rhythms under constant laboratory conditions (Naylor 1985, Aagaard et al. 1995b). Furthermore, shore crabs have an annual migration pattern, migrating to deeper waters before winter and returning to shallow waters during spring, when water temperature increases to about $8^{\circ} \mathrm{C}$ (Rasmussen 1973).

The shallow water habitats along the coast are highly fluctuating environments and vary in temperature, salinity, oxygen tension, light intensity and hydrostatic pressure in relation to tidal and diel changes. This necessitates a continuous adjustment of animals occupying these habitats. The 2 colour forms of shore crabs apparently have different strategies for dealing with such variations. In general, females and red males try to avoid these changes by staying in the subtidal zone, where changes are less pronounced. In contrast, green males often migrate into shallow waters twice a day with the incoming tide to forage, perhaps to avoid competition from larger red males. Several studies demonstrate that green males are physiologically better adapted to withstand the fluctuations in abiotic factors typical for the intertidal zone than are red males. For example, Reid \& Aldrich (1989) found that green shore crabs are more tolerant to hypoxia than are red crabs. Apparently, green shore crabs are also better osmoregulators, and they have higher survival rates than red crabs when exposed to low salinities (Reid et al. 1989).

The Isefjord is the second largest fjord system in Denmark, with large populations of shore crabs (Rasmussen 1973). It is a low salinity, weakly tidal, shallow water fjord with maximum water depth of $12 \mathrm{~m}$. In this fjord, the general weather conditions and especially the wind often have a larger effect on water level than the tide, and large seasonal variations in temperature and salinity are common (Royal Danish Administration of Navigation and hydrography). The fjord system therefore is an irregulariy fluctuating environment, and animals living in habitats related to the fjord must constantly adjust to this changing environment.

The present study was undertaken to investigate how different colour forms of shore crabs respond to such irregular changes in their natural habitat. Heart rate and locomotor activity were monitored continuously in relation to naturally occurring changes in light intensity, temperature, salinity and water depth. The experiments were conducted during 2 periods, 1 month during summer and 1 month during late autumn, to investigate further the importance of seasonal variations on these aspects of shore crab physiology and behaviour.

\section{MATERIALS AND METHODS}

The field experiments were carried out in the Isefjord. The first experimental period extended from July 7 to August 8 and covered a total of 4 experiments. The second experimental period was from October 18 to November 25 and also consisted of 4 separate experiments. All 8 experiments were performed with adult male shore crabs Carcinus maenas. During summer, average size (carapace width, $\mathrm{CW}$ ) for green and red crabs was $63 \pm 6 \mathrm{~mm}$ and $64 \pm 7 \mathrm{~mm}$, respectively. During autumn, CW for green crabs was $60 \pm 9 \mathrm{~mm}$ and $\mathrm{CW}$ for red crabs was $62 \pm 7 \mathrm{~mm}$.

Crabs were caught in unbaited eelnets in the Isefjord and placed in individual chambers in the experimental box approximately $24 \mathrm{~h}$ before experimentation. The box was made of non-transparent polystyrene positioned in an aluminium frame, and divided into individual chambers by the use of non-transparent plastic. The aluminium frame was placed in the sediment so that the crabs were approximately $50 \mathrm{~cm}$ below water level during low tide and $1.5 \mathrm{~m}$ during periods with maximum water level. In order to prevent the crabs from escaping, the box was closed with a steel net. This also prevented objects in the water from entering the chambers.

Measurements of heart rate and locomotor activity. A computer system previously described by Depledge \& Andersen (1990) and modified by Bojsen et al. (1998) was used for in situ measurements of heart rate and locomotor activity using infrared sensors (emitter/ detector). The sensors for measuring heart rates were attached on the dorsal part of the carapace over the cardiac region. The light from the emitter passes through the carapace and is reflected back to the detector during heart contraction. To monitor locomotor activity, 2 sensors were placed underneath the transparent floor of each experimental chamber. Locomotor activity was detected when the crabs stimulated 1 or both sensors. The sensors were positioned so that the crabs could not move significantly without stimulating at least 1 of the sensors. All data were recorded continuously and stored on the computer every minute.

Measurements of temperature, depth, salinity and light. Temperature $\left({ }^{\circ} \mathrm{C}\right)$, salinity (ppt) and depth (m) were measured with a computer-controlled underwater probe placed in the experimental box. Relative changes in light intensity (measured in volts) were recorded with a photodiode also placed in the box. Every minute, data for all 4 variables were stored on a computer.

Data analysis. In all experiments, data for the first $24 \mathrm{~h}$ were discarded to exclude stress from handling. Reduced time series of 30 min averages were used during all data treatments. For both heart rate and loco- 
motor activity, periodogram analysis was used to calcu late the periodicity of each individual time series (Williams \& Naylor 1978). The presence of periodicity in the reduced time series was investigated for the interval 8 to $32 \mathrm{~h}$, since both tidal and diurnal rhythms were expected. The periodicity of the original data is indicated by the highest standard deviations (S).

For each individual time series, Student's $t$-test and 2-way ANOVA were used to test for significant differences in heart rate between high tide and low tide and between night and day.

Path analysis was used to evaluate the relative influence of other measured variables on variations in heart rate levels in red and green crabs in each experiment. Path analysis describes the correlations between changes in heart rate (criterion variable) and changes in light, depth, temperature, salinity and locomotor activity (predictor variables). Path diagrams, based on multiple regression techniques and least square estimation, were calculated as described by Sokal \& Rohlf (1995). A model for the a prion hypothetical relationship between criterion variables and predictor variables was defined, and path coefficients ( $\beta$-weights) were then calculated by a backward elimination procedure. This results in the simplest model explaining the data observed. It was not possible to perform 1 path analysis for all experiments in each season. For this reason, a combined path diagram for each colour and season is presented. This includes the range in which path coefficients were obtained for each relation between criterion variables and predictor variables.

\section{RESULTS}

\section{Rhythmic behaviour in relation to season}

Fig. 1 shows 4 examples of time series for heart rate $\left(f_{\mathrm{H}}\right)$ and locomotor activity $\left(a_{\mathrm{L}}\right)$ in green (Fig. $1 \mathrm{a}, \mathrm{d}$ ) and red (Fig. 1b,e) shore crabs Carcinus maenas, recorded during summer (Fig. 1a,b,c) and autumn (Fig. 1d,e,f). Also shown are the simultanuous recordings of the abiotic variables, light, temperature, depth and salinity (Fig. 1c,f). The figure demonstrates circatidal rhythms in both red and green crabs during summer, with heart rates and locomotor activity levels being higher during high tide than during low tide. An example of a circadian modulation of a circatidal rhythm in heart rate and locomotor activity can be observed in Fig. 1b. In this individual, the increases in heart rate and locomo-
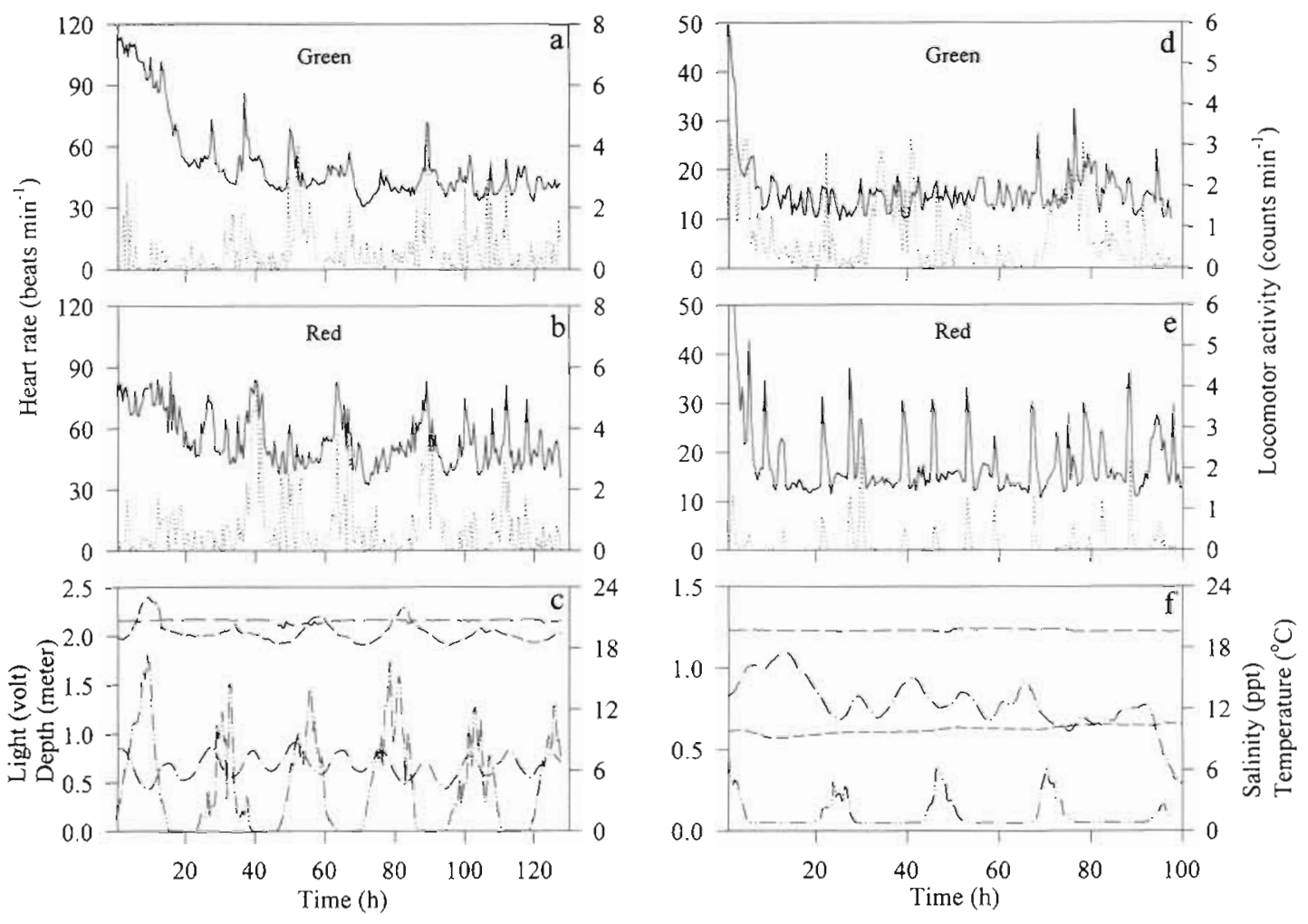

Fig. 1. Carcinus maenas. Heart rate (beats $\mathrm{min}^{-1}$ ) and locomotor activity (counts $\mathrm{min}^{-1}$ ) in 4 crabs monitored during (a,b) summer and $(d, e)$ autumn in relation to $(c, f)$ abiotic variables. $(a, d)$ Green crabs and (b,e) red crabs. - - heart rate;

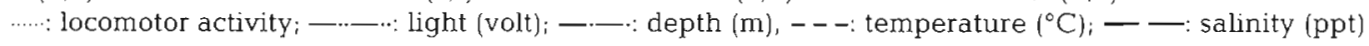


tor activity induced by high tide were larger when the high tide occurred at night than when it occurred during the day.

For both colour forms, heart rate and locomotor activity levels were clearly lower during autumn than during summer. Also, variations in heart rate and locomotor activity were less pronounced and circatidal and circadian rhythmicity was less evident. This is further demonstrated in Fig. 2, which shows average time series of heart rate and locomotor activity for 2 experiments each recorded during summer (Fig. 2a) and autumn (Fig. 2 d) for both colour forms of crabs. Also shown are the periodogram analyses for the 2 time series. During summer, circatidal and circadian variations in both heart rate and locomotor activity can be observed, and the periodograms show a significant periodicity $(\mathrm{p}<0.05)$ of approximately 12.5 and $24 \mathrm{~h}$ for both heart rate (Fig. 2b) and locomotor activity (Fig. 2c), indicating the presence of circatidal and circadian rhythmicity in the time series. The periodogram analyses for the time series recorded during autumn illustrate the absence of circatidal rhythmicity since periodicities of approximately $12.5 \mathrm{~h}$ in heart rate and locomotor ac- tivity were not observed (Fig, 2e,f). A significant periodicity of approximately $24 \mathrm{~h}$ could be demonstrated in heart rate but not in locomotor activity.

Table 1 summarises the occurrence of periodicity in heart rate and locomotor activity for all crabs investigated $(p<0.05)$. With few exceptions, the length of periodicity was 11.5 to $13.5 \mathrm{~h}$ and 22 to $26 \mathrm{~h}$ for both heart rate and locomotor activity, indicating that periodical variations in these parameters may be associated with natural tidal and diurnal variations in depth and light intensity. Table 1 also demonstrates that periodicity is more common during summer than during autumn. For heart rate 11 of 23 crabs and 5 of 21 crabs expressed a periodicity of approximately $12.5 \mathrm{~h}$ in summer and late autumn, respectively. A similar periodicity was observed for locomotor activity in 6 and 1 individuals during summer and autumn, respectively. During summer, 14 crabs expressed a rhythmicity in heart rate of around $24 \mathrm{~h}$. During autumn, 6 crabs expressed a periodicity in heart rate of approximately $24 \mathrm{~h}$. For locomotor activity, periodicity of approximately $24 \mathrm{~h}$ occurred in 13 crabs and 5 crabs in summer and autumn, respectively.
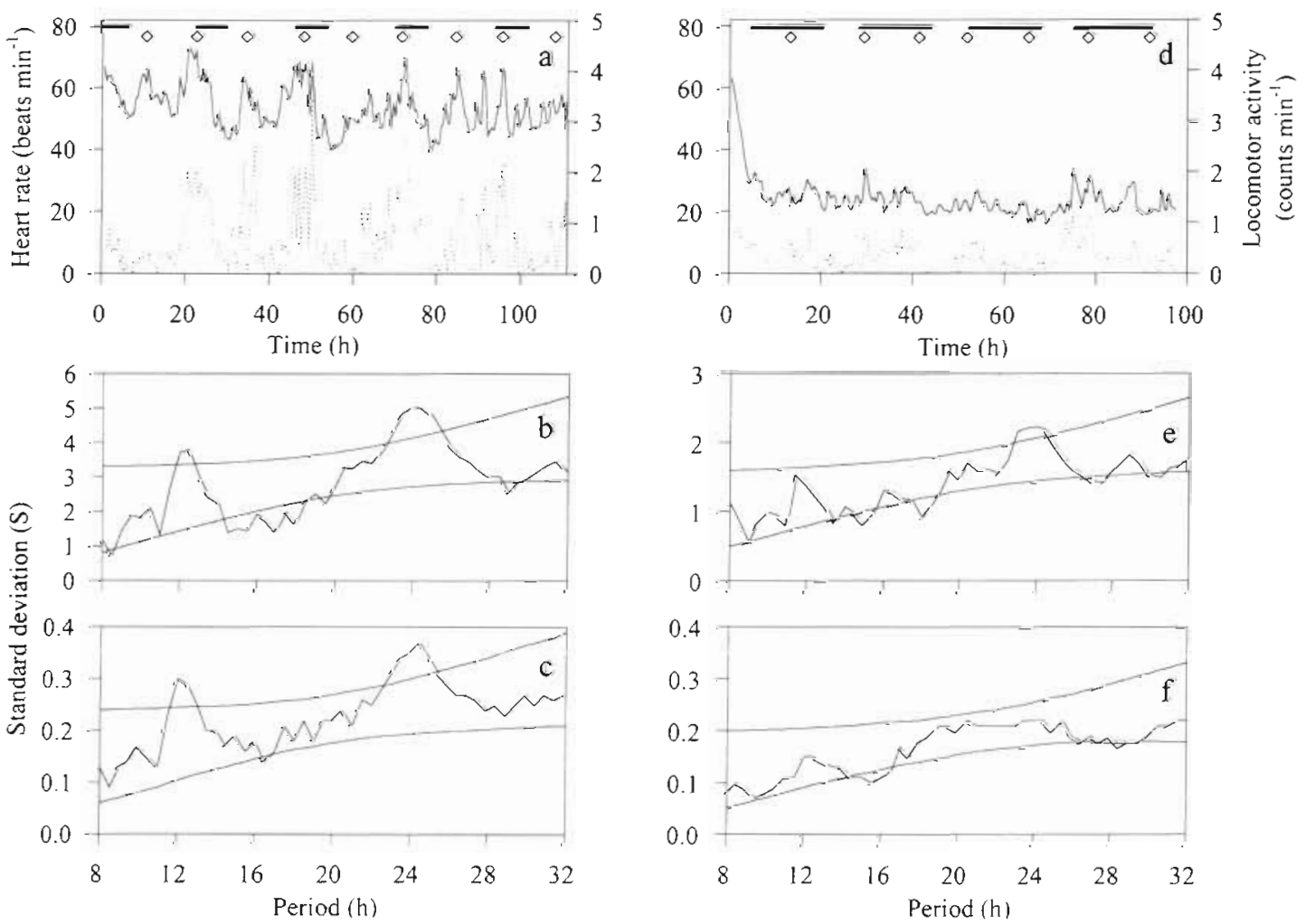

Fig. 2. Carcinus maenas. Average $(n=8)$ time series of heart rate (beats $\min ^{-1}$ ) and locomotor activity (counts min ${ }^{-1}$ ) for (a) 1 experiment recorded during summer and (d) 1 experiment recorded during autumn. Black horizontal bars indicate night periods. Diamonds indicate high tide. Also shown are the periodograms obtained from the time series. Summer: (b) heart rate; (c) locomotor activity. Autumn: (e) heart rate; (f) locomotor activity. Curved lines are 95\% confidence limits of the randomized data. Standard deviations above this are significant $(\mathrm{p}<0.05)$ 
Table 1. Carcinus maenas. Occurrence of periodicity in time series of heart rate and locomotor activity in all crabs, calculated from periodogram analysis. Only significant periodicities are shown ( $\mathrm{p}<0.05$ ). Carapace width (CW) for individual crabs is also shown. np: no periodicity was observed in the time series

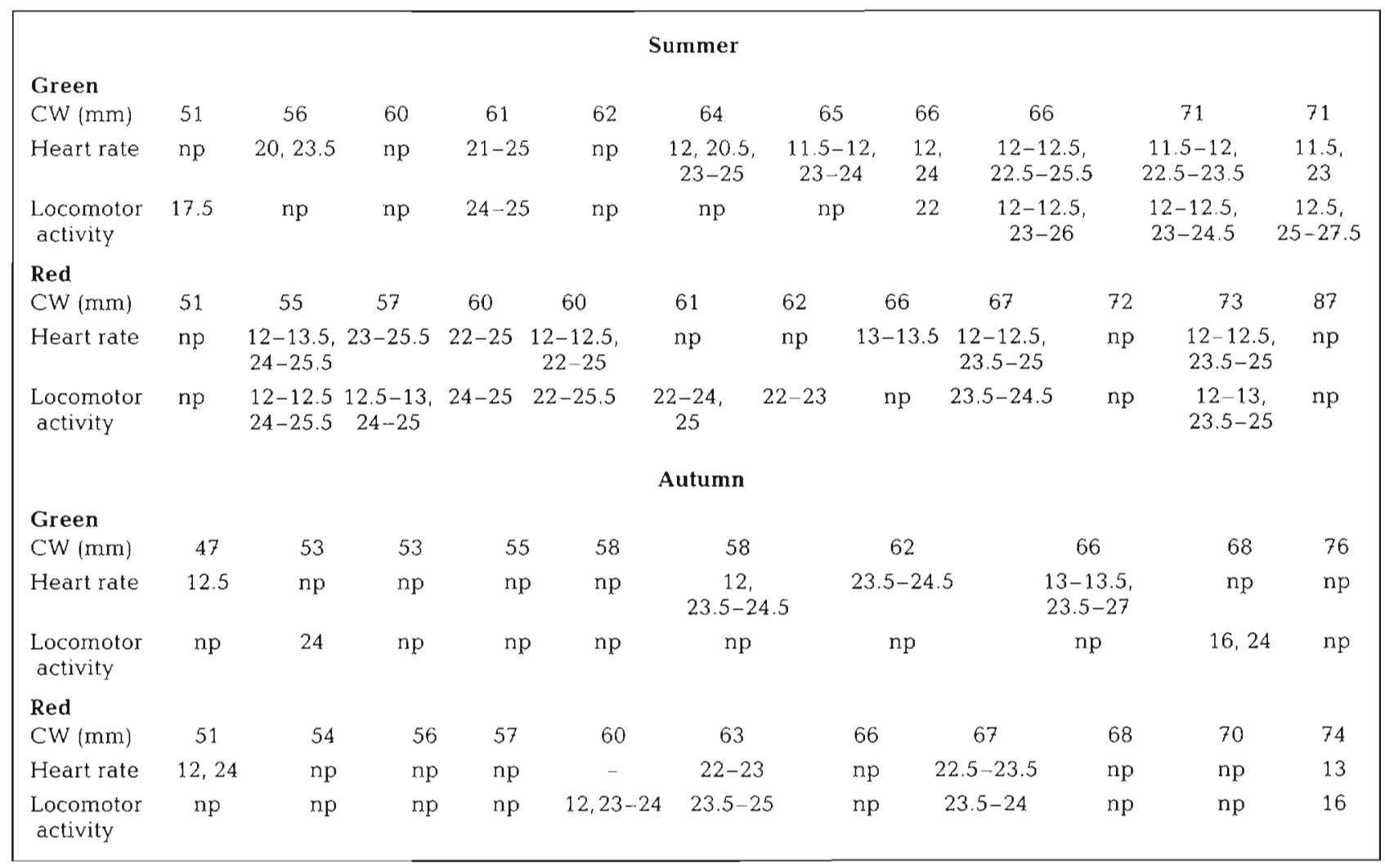

\section{Expression of circatidal and circadian rhythmicity in relation to colour}

Fig. 3 shows average time series for green (Fig. 3a, b,c) and red (Fig. 3d,e,f) shore crabs from an experiment performed during summer. Also shown are the periodograms for heart rate and locomotor activity. The figure demonstrates a tendency towards circatidal rhythms in green crabs and a tendency towards circadian rhythms in red crabs.

Table 2 shows average heart rates in relation to tide and light cycles for all 43 crabs recorded during summer and autumn. For both colour forms, heart rate levels were significantly higher during summer than during autumn ( $\mathrm{p}<0.001)$. Also, more crabs expressed rhythmicity during summer, thus 9 green crabs $(82 \%)$ and 6 red crabs (50\%) expressed rhythmicity directly related to tide or light cycles. As opposed to this, 6 green crabs (60\%) and 3 red crabs $(30 \%)$ expressed rhythmicity in heart rate during autumn.

Rhythmic variations in heart rate were significantly higher in more green crabs than red crabs in both summer and autumn (Table 2). This was especially true for circatidal rhythms. During summer, 5 green crabs
(45\%) had significantly higher heart rate levels at high tide than at low tide. This was observed in only 2 red crabs (17\%). During autumn, 3 green crabs $(30 \%)$ had significantly higher heart rates during high tide than during low tide $(p<0.05)$. This was never observed in red crabs. Significantly higher heart rate levels during low tide than during high tide were never observed in any colour form or season.

The diurnal variation in heart rate also differed between the colour forms. In the experiments performed during summer, 5 green (45\%) and 5 red crabs (42\%) expressed a diurnal variation in heart rate. However, in 4 green crabs, heart rate levels were higher during the night, and only 1 individual had higher heart rate levels during the day. In contrast, 2 red crabs had higher heart rate levels during the night, whereas 3 individuals had higher heart rate levels during the day. During autumn, circadian rhythmicity in heart rate was observed in 4 green $(40 \%)$ and 3 red (30\%) crabs.

In general, both circatidal and circadian rhythmicities in heart rate were commonly observed in green shore crabs, whereas circadian rhythmicity was the most common type of rhythm observed in red crabs. 

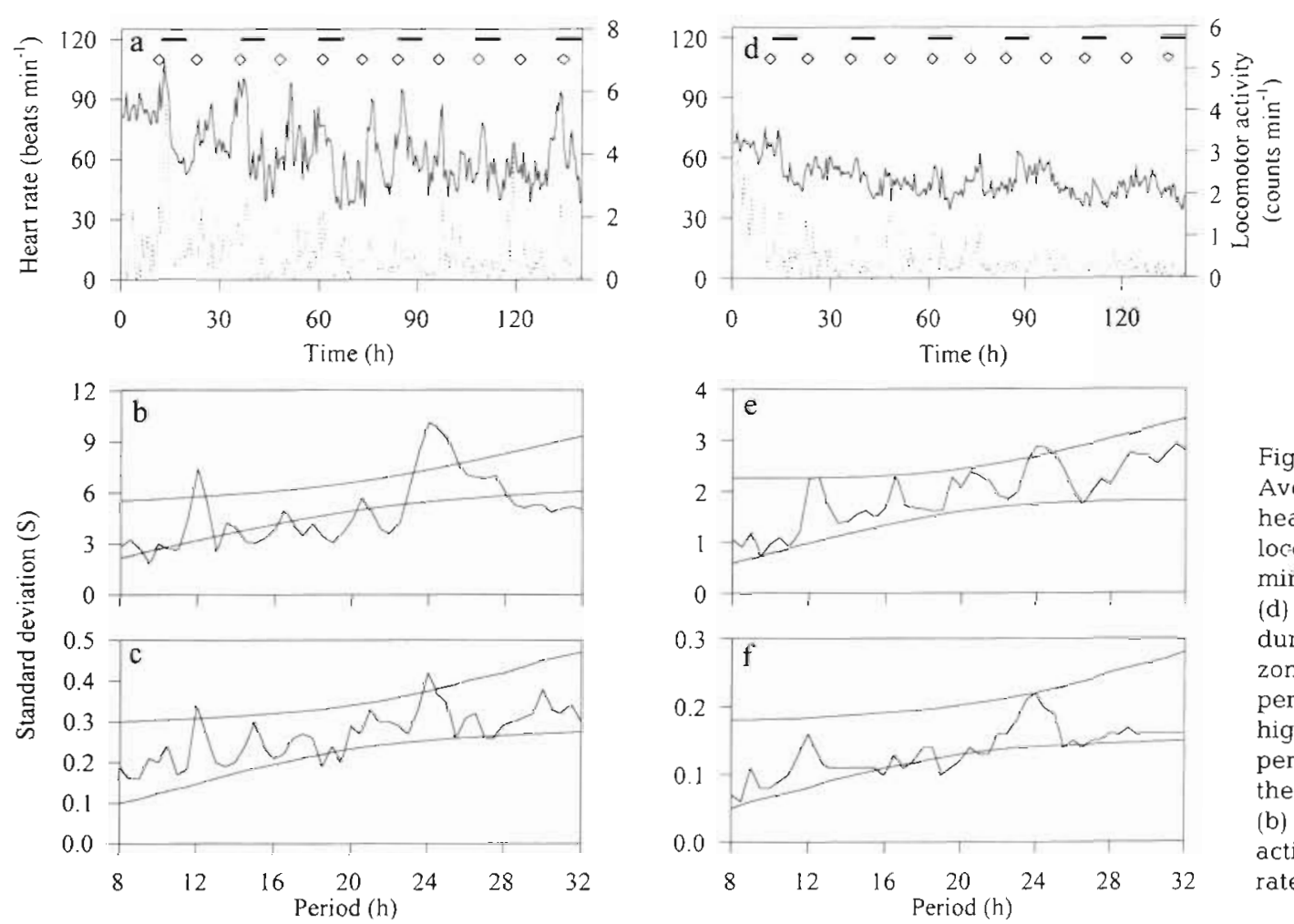

Fig. 3. Carcinus maenas Average $(\mathrm{n}=4)$ time series of heart rate (beats $\mathrm{min}^{-1}$ ) and locomotor activity (counts $\mathrm{min}^{-1}$ ) for (a) green and (d) red shore crabs recorded during summer. Black horizontal bars indicate night periods. Diamonds indicate high tide. Also shown are the periodograms obtained from the time series. Summer: (b) heart rate; (c) locomotor activity. Autumn: (e) heart rate; (f) locomotor activity

Table 2. Carcinus maenas. Average heart rate (beats $\min ^{-1}$ ) recorded during high tide (HT), low tide (LT), night and day for all crabs. Carapace width (CW) for individual crabs is also shown

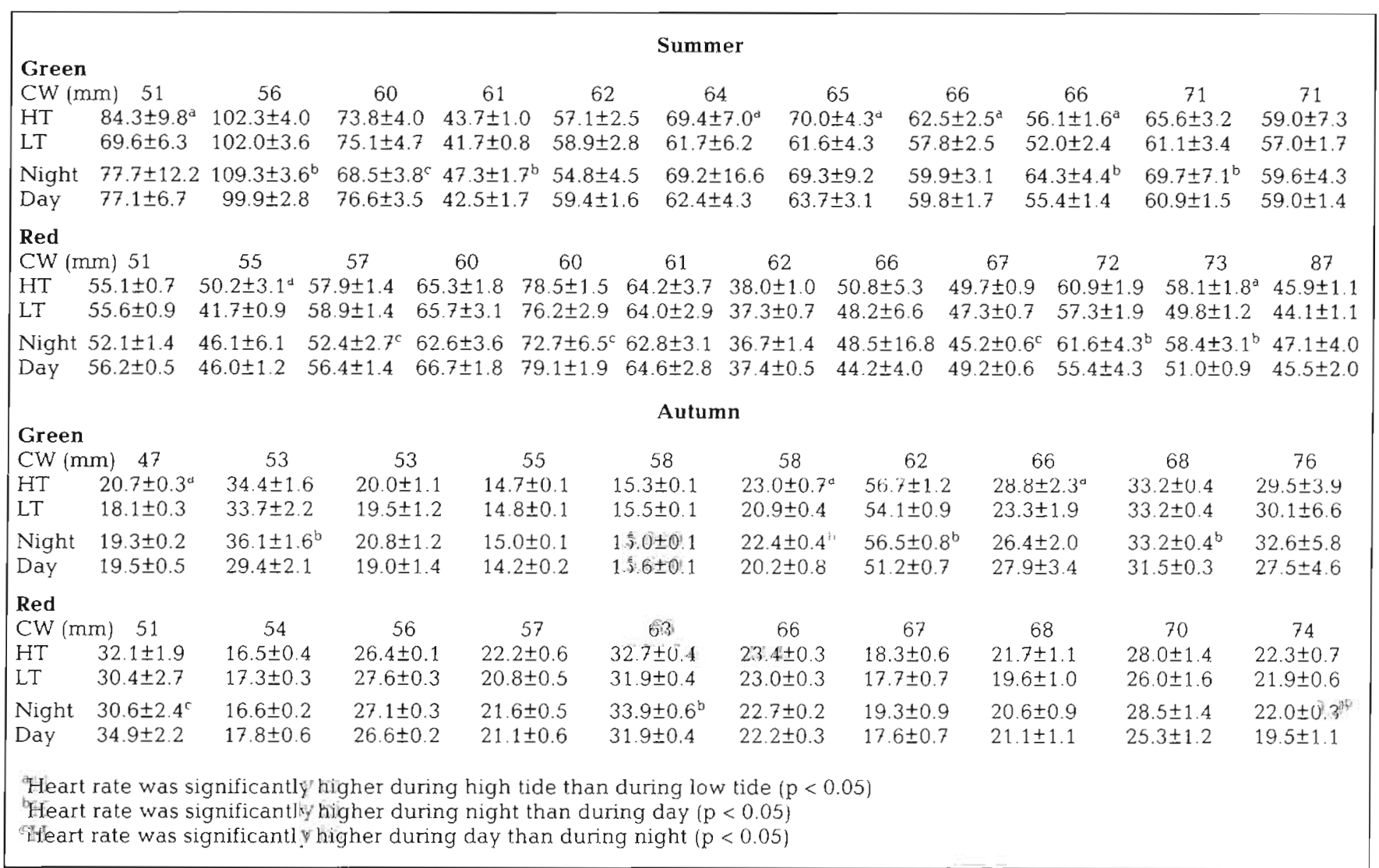



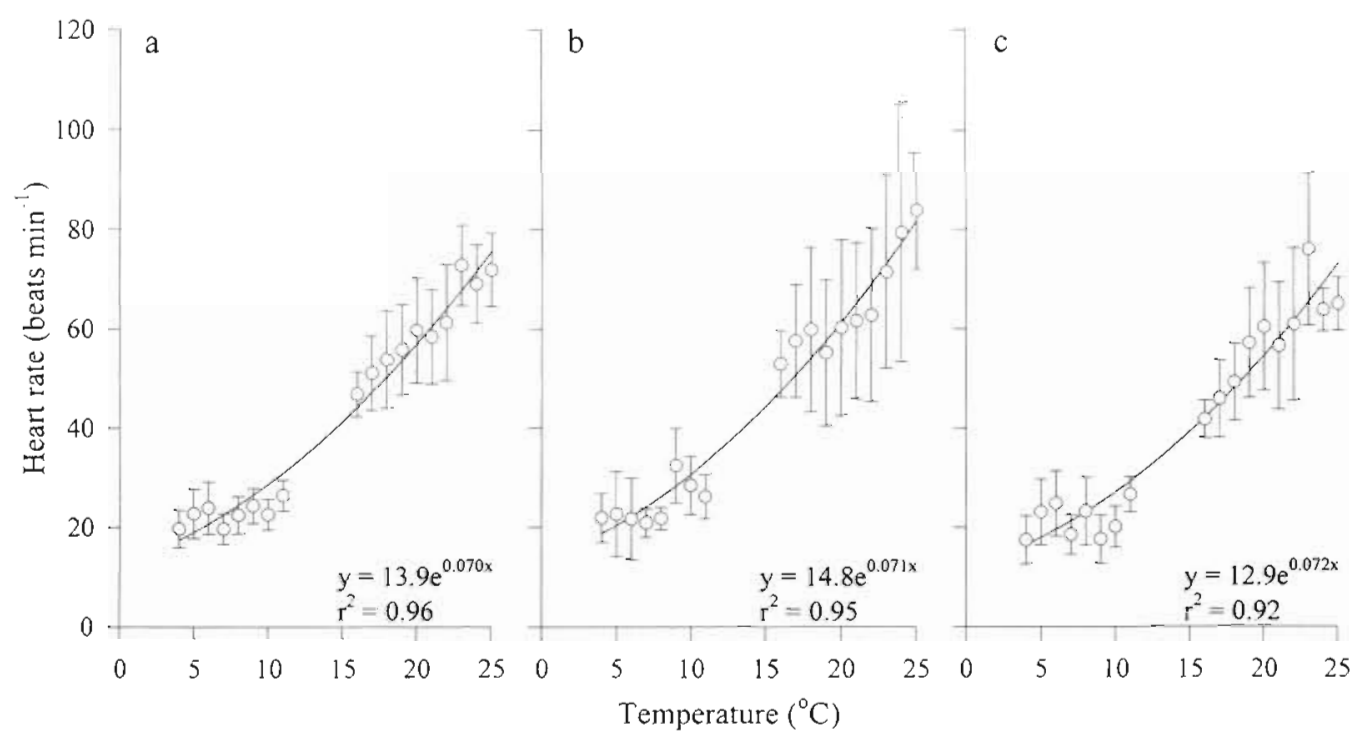

Fig. 4. Carcinus maenas. Correlation between temperature $\left({ }^{\circ} \mathrm{C}\right.$ ) and heart rate (beats $\left.\mathrm{min}^{-1} \pm \mathrm{SD}\right)$ for $(\mathrm{a})$ green + red crabs, $(\mathrm{b}) \mathrm{green}$ crabs and (c) red crabs. Exponential equations for the fitted curves are shown

\section{Influence of temperature on in situ heart rate levels}

Fig. 4 examines the correlation between heart rate and temperature for both experimental periods. In summer, temperature varied between 16 and $25^{\circ} \mathrm{C}$ during the experimental period. During autumn, temperature varied between 4 and $11^{\circ} \mathrm{C}$. Fig. 4 a shows the correlation for both green and red crabs, whereas Fig. 4b,c shows the correlation for green and red crabs separately. In all cases, heart rate was found to increase with increasing temperature. In general, heart rates for green crabs were higher than for red crabs, but this was not significant.

The figure also shows the equations for the fitted curves. From these equations, $Q_{10}$ values for heart rate in green and red shore crabs were calculated. $Q_{10}$ for green and red crabs together was 2.14. Calculated separately for green and red crabs the $Q_{10}$ values were 2.16 and 2.18, respectively, but they were not significantly different.

\section{Relative influence of abiotic factors on heart rate and locomotor activity}

Fig. 5 shows the path diagrams for green (Fig. 5a) and red crabs (Fig. 5b) for all 4 experiments performed during summer. In both colour forms, heart rate (criterion variable) was found to be influenced directly or indirectly by all predictor variables (locomotor activity, temperature, light intensity, depth and salinity). The $\beta$-weights show that locomotor activity exerted the greatest influence on heart rate, followed by temperature, depth, salinity and light intensity. This was found in both colour forms. Also in both colour forms, locomotor activity was directly influenced by variations in light, temperature and depth, whereas changes in salinity exerted no influence.

The path diagram obtained for green crabs differs from that obtained in red crabs in 2 ways. In 1 experiment, light intensity exerted a direct negative effect on heart rate in green crabs, whereas no direct effect of light on heart rate was observed in red crabs. In both colour forms, light indirectly exerted a positive effect on heart rate by exerting a positive effect on water temperature. Depth was found only to exert a positive effect on locomotor activity in green crabs. This is in contrast to red crabs, where depth was found to exert positive effects on locomotor activity in some individuals and negative effects in others.

The combined path diagrams obtained for the experiments performed during autumn (Fig. 6) are simpler than those obtained during summer. In both green and red crabs, light, temperature and salinity influenced heart rate, whereas depth did not affect heart rate significantly. Also, the influences of abiotic factors on locomotor activity were less pronounced. In green crabs none of these variables were found to influence locomotor activity, and in red crabs a weak but significant negative effect of light on locomotor activity was observed.

In general, locomotor activity, temperature, depth and salinity were positively related to heart rate, whereas light generally was negatively related to heart rate. 


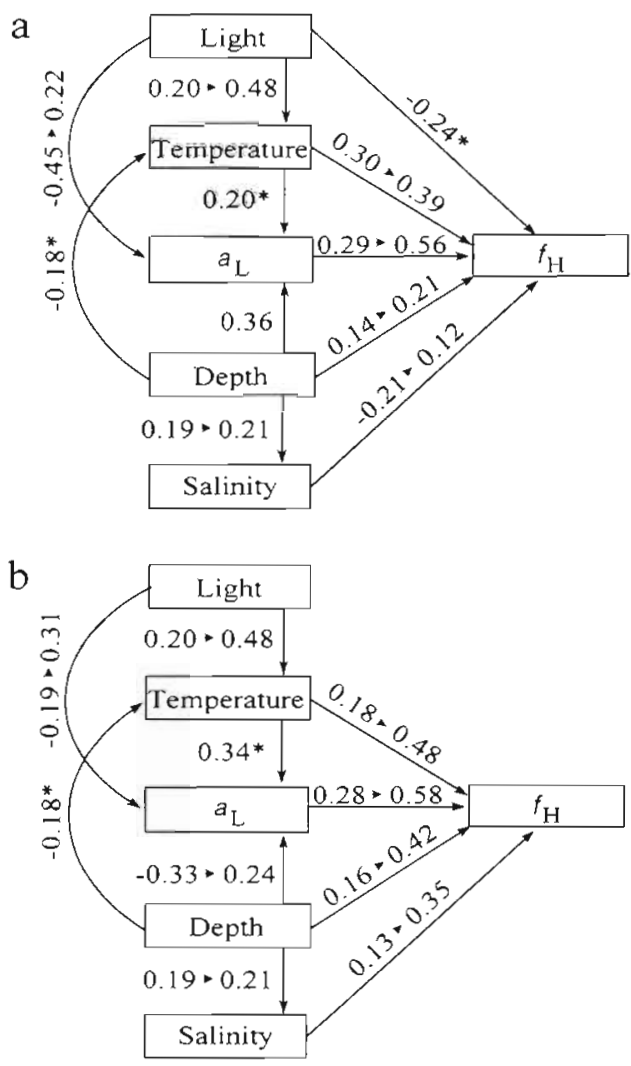

Fig. 5. Carcinus maenas. Path diagrams for (a) green and (b) red shore crabs calculated from time series recorded during summer. Values associated with the arrows are path coefficients ( $\beta$-weights). Only statistically significant path coefficients are shown $(p<0.05)$ *A significant relationship was only observed in 1 experiment

\section{DISCUSSION}

The present experiments demonstrate that circatidal and circadian rhythmicity in heart rate and locomotor activity is expressed in situ in both green and red colour forms of the shore crab Carcinus maenas. They also demonstrate that circatidal as well as circadian rhythms in physiology and behaviour are common in green male shore crabs, whereas red crabs predominantly express circadian rhythmicity and only to a lesser extent express circatidal rhythms. This difference in heart rate and locomotor activity between green and red crabs has previously been described in the laboratory (Reid et al. 1993, Aagaard et al. 1995b) but has not previously been quantified from simultaneous monitorings of heart rate and locomotor activity in situ. This is also consistent with a field study from a weakly tidal habitat in which green shore crabs expressed both circatidal and circadian migration patterns on the shore, whereas red crabs predominantly expressed a circadian migration pattern (Aagard et al. 1995a).

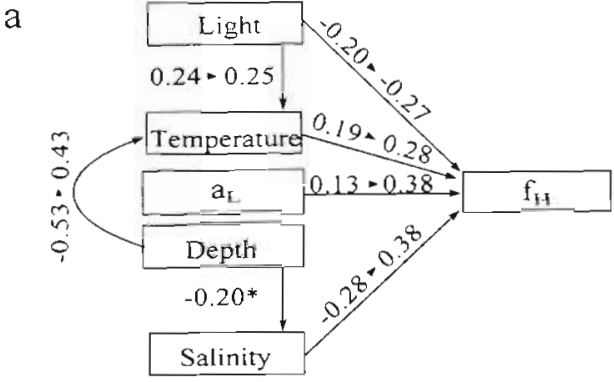

b

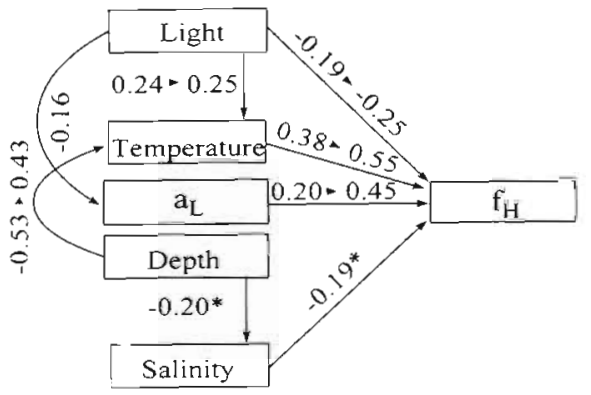

Fig. 6. Carcinus maenas. Path diagrams for (a) green and (b) red crabs calculated from time series recorded during autumn. Values associated with the arrows are path coefficients ( $\beta$-weights). Only statistically significant path coefficients are shown $(p<0.05)$. *A significant relationship was only observed in 1 experiment

As rhythmicity was equally common in larger and in smaller crabs, the differences in rhythmic behaviour are likely to be related to differences in colouration and not to differences in size.

The expression of rhythms in physiology and behaviour is of great adaptive value. Due to their larger body size, thicker carapace and heavier chelae (Kaiser et al. 1990, McGaw et al. 1992), red crabs may be able to partly displace green male crabs from the subtidal zone into the intertidal zone. Foraging at high tide is therefore a major advantage for green shore crabs, since this is a period at which the crabs are less vulnerable to avian predation, especially from sea gulls that prey on several intertidal crab species including Carcinus maenas (Dumas \& Witman 1993). Furthermore, shore crabs may express a circadian modulation of circatidal rhythm, being more active at those high tides occurring during nighttime than during daytime, which further reduces the risk of predation from birds and fish using vision for hunting. This may also explain why nocturnal behaviour is commonly observed in red male shore crabs.

The expression of rhythmicity in physiology and behaviour appears to depend on season. During autumn, rhythmicity could be observed in heart rate as well as locomotor activity, but rhythmicity was observed in 
fewer individuals, and the rhythm itself was less pronounced (Tables 1 \& 2). In combination with the lower heart rate and locomotor activity levels observed, this may demonstrate a general drop in activity during late autumn and winter. In laboratory experiments with freshly caught shore crabs, Atkinson \& Parsons (1973) found that crabs collected during summer expressed endogenous circatidal rhythmicity in locomotor activity, whereas crabs collected during autumn failed to express endogenous circatidal rhythmicity in locomotor activity. Furthermore, Atkinson \& Parsons (1973) found circadian rhythmicity in shore crab behaviour at all times of the year, but to a lesser extent during autumn, as also observed in the present study. Using baited dropnets along a transect through the tidal zone during late autumn, Aagaard et al. (1995a) caught a larger fraction of total catch of shore crabs during night than during the day. During summer, however, average catch per dropnet was similar during night and day, indicating that foraging behaviour is related to the tidal and diurnal cycles during summer, but primarily related to nocturnal behaviour during late autumn, as is also indicated by the present study.

One of the factors explaining why shore crabs are less active and largely suspend rhythmic behaviour during late autumn is presumably temperature. As crabs are poikilotherms, their metabolism decreases with ambient temperature, reducing both the general activity level of the crabs and their food demand. This may lead to a partial suspension of rhythmic behaviour often related to foraging.

For the temperature range 16 to $20^{\circ} \mathrm{C}$, Aagaard (1996) estimated $Q_{10}$ values for heart rate in shore crabs in situ to be 3.5 to 4.0 , which is higher than observed in the present study for the temperature range of 4 to $25^{\circ} \mathrm{C}$. However, for the temperature interval 4 to $20^{\circ} \mathrm{C}$, heart rate was observed to increase at a higher rate $\left(Q_{10}=2.7\right.$ for red crabs and $Q_{10}=2.4$ for green crabs). These $Q_{10}$ values are higher than those calculated for heart rate in shore crabs in laboratory experiments $\left(Q_{10}=2\right)$ (Ahsanullah \& Newell 1971). In the prawn Palaemon elegans, Morris \& Taylor (1984) also found higher $Q_{10}$ values $\left(Q_{10}=2.24\right)$ in situ than in laboratory experiments $\left(Q_{10}=1.78\right)$. Several factors may contribute to the greater temperature sensitivity of animals in the field than in the laboratory. Differences in nutritional state, chemical stimuli from food and predators, and the presence of several entrainment factors may increase the response to temperature changes in situ.

For the temperature interval 16 to $20^{\circ} \mathrm{C}$ the heart rate increased more rapidly in red crabs than in green crabs. However, the rate increase levelled off in the temperature interval of 20 to $25^{\circ} \mathrm{C}$ in red crabs but not in green crabs. This may indicate a tolerance to higher temperatures in green shore crabs than in red shore crabs. This may have an adaptation value, since green shore crabs are commonly found in shallow water during the day where temperature may be as high as $25^{\circ} \mathrm{C}$, whereas red crabs are primarily found subtidally where temperature rarely exceeds $20^{\circ} \mathrm{C}$. This aspect of shore crab physiology awaits further investigation.

In laboratory experiments, Ahsanullah \& Newell (1971) found $Q_{10}$ of heart rate in shore crabs for the interval 5 to $15^{\circ} \mathrm{C}$ to be above 2, whereas $Q_{10}<1.55$ for the interval 20 to $30^{\circ} \mathrm{C}$. This, in conjunction with the present experiments, may indicate that temperatures above approximately $20^{\circ} \mathrm{C}$ are suboptimal for shore crabs and that circulation primarily is adapted for functioning at temperatures below the summer maxima of approximately 20 to $25^{\circ} \mathrm{C}$

The present experiments suffer from the fact that $Q_{10}$ values could not be calculated in individual crabs, since temperature changes were relatively small within each experiment $\left(4\right.$ to $7^{\circ} \mathrm{C}$ during summer and 2 to $4^{\circ} \mathrm{C}$ during autumn) and occurred in a diurnal manner. However, Fig. 4 provides important ecophysiological information about $Q_{10}$ values for shore crabs in general, since large temperature changes in the habitat are most likely associated with changes over seasons. This is in contrast to several laboratory experiments where crabs are often exposed to large changes in temperature within a relatively narrow timespan.

The path diagrams (Figs. $5 \& 6$ ) show that several factors possibly influence both heart rate and locomotor activity in shore crabs in situ and that the entrainment of circatidal and circadian rhythmicity is related to other variables such as season and inter-moult duration, i.e. colour of the crabs.

In general, light was observed to exert a negative effect on heart rate and locomotor activity, especially during autumn (Figs. $5 \& 6$ ), and this is likely to entrain the observed nocturnal behaviour of shore crabs (Aschoff 1963, Reid \& Naylor 1990). However, the influence of light is complex, and increased light intensity was frequently observed to exert a positive effect on heart rate and locomotor activity, especially in red crabs during summer. This variable response conceivably explains the relatively low direct effect of light on heart rate in the path diagrams for summer (Fig. 5). Aagaard (1996) also observed an overall negative effect of light on in situ heart rates of shore crabs during summer. However, Aagaard (1996) observed a positive correlation between heart rate and light intensity during daytime. This may be interpreted as an escape response of the crabs, trying to avoid the light during periods with high light intensities and thereby exposure to predators, and is further emphasised by the fact that this response was absent during autumn, i.e. when light intensity is lower than in summer. 
In each experiment, the effect of temperature on heart rate and locomotor activity was related to diurnal variations in light intensity (Figs. $1 \& 2$ ), which is somewhat different from those effects described in Fig. 4 which are related to seasonal temperature changes. In each experiment, temperature exerted the greatest effect on heart rate and locomotor activity of all abiotic variables measured (Figs. $5 \& 6$ ), and was slightly higher during summer than during autumn, when light intensities and therefore temperature variations were lower. This indicates that temperature may serve as an entrainment factor, increasing general metabolism and promoting higher heart rate and locomotor activity levels during the day than during the night, especially during summer when diurnal variations in temperature are larger than during autumn.

Salinity was the abiotic factor exerting the lowest effect on heart rate and did not exert any direct effect on locomotor activity in any experiment. Salinity was previously shown to entrain circatidal rhythms in locomotor activity (e.g. Taylor \& Naylor 1977, Bolt \& Naylor 1985, McGaw \& Naylor 1992), but in those studies, the salinity changes were much larger ( 14 to $34 \%$ ) than in the present in situ study ( 1 to $3 \%$ ), explaining the weak influence of salinity in this study.

The path diagrams show that water temperature almost entirely depends on light intensity during summer but is also influenced by depth during autumn, which again may influence the physiology and behaviour of shore crabs. This is probably related to the geographical location of the field site. The Isefjord is located on the island of Zealand and opens to the sea of Kattegat which is situated between the North Sea and the Baltic Sea. During summer, western winds dominate and tend to transport colder water into the fjord from the North Sea. During late autumn and winter, eastern winds (that often dominate in late autumn and winter) will transport cold water into the fjord system from the Baltic Sea, whereas western winds tend to transport relatively warm water from the North Sea and the Atlantic Ocean into the fjord (Royal Danish Administration of Navigation and Hydrography). This further adds to the complexity of this environment.

The path diagrams demonstrate that shore crabs (in particular green shore crabs) also relate to natural changes in depth, with higher activity levels during high tide than during low tide. This response has been suggested to be mediated by changes in hydrostatic pressure (Naylor \& Atkinson 1972, Reid \& Naylor 1990). In the present study, the tidal changes in depth were usually less than $0.5 \mathrm{~m}$, equivalent to changes in pressure of approximately $5 \mathrm{kPa}$. Apparently, this is sufficient to entrain a circatidal rhythm in heart rate and locomotor activity in shore crabs. This is somewhat different from that of true estuaries, where circatidal patterns of locomotion appear to be entrained by large increases in hydrostatic pressure and salinity, and decreased temperature (Naylor \& Williams 1984, Bolt \& Naylor 1985).

Depth was found to have a larger influence on heart rate and locomotor activity during summer than during autumn, and red crabs were sometimes found to relate in a negative manner to changes in depth, demonstrating that in weakly tidal habitats circatidal rhythms are most commonly observed in green crabs, whereas nocturnal behaviour is most commonly observed in red crabs.

Acknowledgements. We are grateful to Maria F. Petersen for long hours of assistance during the collection of field data. This work was supported by grants from the Danish Natural Science Research Council to B.S. and O.A.

\section{LITERATURE CITED}

Aagaard A (1996) In situ variation in heart rate of the shore crab Carcinus maenas in relation to environmental factors and physiological condition. Mar Biol 125:765-772

Aagaard A, Warman CG, Depledge MH (1995a) Tidal and seasonal changes in the temporal and spatial distribution of foraging Carcinus maenas in the weakly tidal littoral zone of Kerteminde Fjord, Denmark. Mar Ecol Prog Ser $122: 165-172$

Aagaard A, Warman CG, Depledge MH, Naylor E (1995b) Dissociation of heart rate and locomotor activity during the expression of rhythmic behaviour in the shore crab Carcinus maenas. Mar Freshw Behav Physiol 26:1-10

Ahsanullah M, Newell RC (1971) Factors affecting the heart rate of shore crab Carcinus maenas (L.). Comp Biochem Physiol 39A:277-287

Aschoff $J$ (1963) Comparative physiology: diurnal rhythms. Annu Rev Physiol 25:581-600

Atkinson RJA, Parsons AJ (1973) Seasonal patterns of migration and locomotor rhythmicity in populations of Carcinus. Neth J Sea Res 7:81-93

Bojsen BH, Witthøfft H, Styrishave B, Andersen O (1998) In situ studies on heart rate and locomotor activity in the freshwater crayfish. Astacus astacus (L.) in relation to natural fluctuations in temperature and light intensity. Freshw Biol 39:101-111

Bolt SRL, Naylor E (1985) Interaction of endogenous and exogenous factors controlling locomotor activity rhythm in Carcinus exposed to tidal salinity changes. J Exp Mar Biol Ecol 85:47-56

Crothers JH (1968) The biology of the shore crab Carcinus maenas (L.). 2. The life of the adult crab. Field Stud 2(5): $579-614$

Dare P, Edwards DB (1981) Underwater television observations on the intertidal movements of shore crabs, Carcinus maenas, across a mudflat. J Mar Biol Assoc UK 61:107-116

Depledge $\mathrm{MH}$, Andersen BB (1990) A computer-aided physiological monitoring system for continuous, long-term recording of cardiac activity in selected invertebrates. Comp Biochem Physiol 96A:473-477

Dumas JV, Witman JD (1993) Predation by herring-gulls (Larus argentatus Coues) on 2 rocky intertidal crab species (Carcinus maenas [L.] and Cancer irroratus Say). J Exp Mar Biol Ecol 169:89-101 
Hunter E, Naylor E (1993) Intertidal migration by the shore crab Carcinus maenas. Mar Ecol Prog Ser 101:131-138

Kaiser MJ, Hughes RN, Reid DG (1990) Chelal morphometry, prey-size, selection and aggressive competetion in green and red forms of Carcinus maenas (L.). J Exp Mar Biol Ecol 140:121-134

McGaw IL, Naylor E (1992) Distribution and rhythmic locomotor patterns of estuarine and open-shore populations of Carcinus maenas. J Mar Biol Assoc UK 72:599-609

McGaw IL, Kaiser MJ, Naylor E, Hughes RN (1992) Intraspecific morphological variation related to the moult-cycle in colour forms of the shore crab Carcinus maenas. J Zool 228:351-359

Morris S, Taylor AC (1984) Heart rate response of the intertidal prawn Palaemon elegans to simulated and in situ environmental changes. Mar Ecol Prog Ser 20:127-136

Naylor E (1985) Tidally rhythmic behaviour of marine animals. Symp Soc Exp Biol 39:63-93

Naylor E, Atkinson RJA (1972) Pressure and the rhythmic behaviour of inshore marine animals. Symp Soc Exp Biol 26:395-415

Naylor E, Williams BG (1984) Environmental entrainment of tidally rhythmic behaviour in marine animals. Zool J Linn Soc 80:201-208

Rasmussen E (1973) Systematics and ecology of the Isefjord marine fauna (Denmark). Ophelia 11:211-221

Reid DG, Aldrich JC (1989) Variation in responses to environmental hypoxia of different colour forms of the shore crab

Editorial responsibility: Otto Kinne (Editor),

Oldendorf/Luhe, Germany
Carcinus maenas (L.). Comp Biochem Physiol 92A: 535-539

Reid DG, Naylor E (1990) Entrainment of bimodal circatidal rhythms in the shore crab Carcinus maenas. J Biol Rhythms 5:333-347

Reid DG, Abelló P, Mc Gaw I, Naylor (1989) Differential tolerances of desiccation and hypo-osmotic stress in sub-and intertidal Carcinus maenas. In: Aldrich JC (ed) Phenotypic responses in aquatic ectotherms. Japaga, Dublin, p 89-96

Reid DG, Warman CG, Naylor E (1993) Ontogenetic changes in zeitgeber action in the tidally rhythmic behaviour of the shore crab Carcinus maenas. In: Aldrich JC (ed) Proc 27th Eur Mar Biol Symp. Japaga, Dublin, p 129-133

Reid DG, Abelló P, Kaiser MJ, Warman CG (1997) Carapce colour, inter-moult duration and the behavioural and physiological ecology of the shore crab Carcinus maenas. Estuar Coast Shelf Sci 44:203-211

Sokal RR, Rohlf FJ (1995) Biometry, 3rd edn. WH Freeman \& Co, Philadelphia, p 609-685

Taylor AC, Naylor E (1977) Entrainment of the locomotor rhythm of Carcinus by cycles of salinity change. J Mar Biol Assoc UK 57:273-277

Warman CG, Reid DG, Naylor E (1993) Variation in the tidal migratory behaviour and rhythmic light-responsiveness in the shore crab Carcinus maenas. J Mar Biol Assoc UK 73 : 355-364

Williams JA, Naylor E (1978) A procedure for assessment of significance of rhythmicity in time-series data. Int $\mathrm{J}$ Chronobiol 5:435-444

Submitted: December 8, 1998; Accepted: March 29, 1999 Proofs received from author(s): October 29, 1999 